\title{
Pharmacovigilance in India and its Impact in Patient Management
}

\author{
${ }^{1}$ Geeta Sharma, ${ }^{2}$ Rahat Kumar, ${ }^{3}$ Jaswinder Singh, ${ }^{4}$ Vikram Bhandari, ${ }^{5}$ Narinder Singh
}

\begin{abstract}
Pharmacovigilance is the pharmacological science relating to the detection, assessment, understanding, and prevention of adverse effects, particularly the long-term and short-term adverse effects of drugs or treatment. The World Health Organization (WHO) established pharmacovigilance Programme for International Drug Monitoring in response to the thalidomide disaster detected in 1961. India joined the $\mathrm{WHO}$ adverse drug reaction (ADR) monitoring program based in Uppsala, Sweden, in 1998. The Central Drugs Standard Control Organization (CDSCO), Directorate General of Health Services, under the aegis of the Ministry of Health and Family Welfare, Government of India, in collaboration with Indian Pharmacopoeia Commission, Ghaziabad, is a National Coordinating Centre (NCC). Adverse drug reaction monitoring centers (AMCs) under the Pharmacovigilance Programme of India (PvPI) play a vital role in the collection and follow-up of ADR reports from the patients, as drug trials in animals and humans (Phase I-III) do not predict accurately the adverse drug events. Patients with chronic kidney disease (CKD)/liver disease are at risk of enhanced drug-related events. These patients should be closely monitored for any adverse events and it should be reported. Thus, inculcating the habit of ADR reporting will help in generating data specific to Indian population and will contribute toward patient safety. This will also help in modifying the treatment given to the patients, as early identification of ADRs will help in reducing morbidity and mortality in patients.
\end{abstract}

Keywords: Adverse drug reactions, Pharmacovigilance, Postmarketing.

How to cite this article: Sharma G, Kumar R, Singh J, Bhandari V, Singh N. Pharmacovigilance in India and its Impact in Patient Management. Curr Trends Diagn Treat 2017;1(1):27-33.

Source of support: Nil

Conflict of interest: None

\section{INTRODUCTION}

The etymological roots of pharmacovigilance are pharmacy and vigilance from the Greek words Pharmakon = Drug and Latin = Vigilare, which mean "To keep awake

\footnotetext{
${ }^{1-3,5}$ Professor, ${ }^{4}$ Associate Professor

${ }^{1-5}$ Department of Pharmacology, Sri Guru Ram Das Institute of Medical Sciences and Research, Amritsar, Punjab, India

Corresponding Author: Geeta Sharma, Professor, Department of Pharmacology, Sri Guru Ram Das Institute of Medical Sciences and Research, Amritsar, Punjab, India, e-mail: r.general173@ yahoo.com
}

or alert, to keep watch" and "To keep watch on drugs, in particular, their safety." The World Health Organization (WHO) defines pharmacovigilance as the pharmacological science and activities relating to the detection, assessment, understanding, and prevention of adverse effects or any other drug-related problems. ${ }^{1,2}$ Consumers, health care professionals (HCPs), pharmaceutical companies, and global regulatory agencies play a significant role in the process of pharmacovigilance. Pharmacovigilance has evolved from largely a record-keeping function, where the purpose was mainly to ensure the processing and submission of individual case reports, to the present, where it now focuses on proactively identifying safety issues and taking appropriate actions to minimize and mitigate risk to the patients. This review highlights the process of pharmacovigilance in adverse event reporting and its impact on patient management and safety.

\section{Pharmacovigilance: Past and Present}

In the early 1900s, the US Food and Drug Administration (FDA) focused mainly on regulatory enforcement on foods that were thought to pose a greater public health problem. However, in 1938, the Food Drug and Cosmetic Act brought cosmetics and medical devices under the control of the FDA and required that drugs be labeled with adequate directions for safe use. ${ }^{3}$ A new breakthrough in the field of pharmacovigilance happened after a single episode in 1937, when sulfanilamide was used for the treatment of streptococcal infections as syrup. It contained diethylene glycol as solvent. This syrup was responsible for the death of 105 patients, and out of them, 34 were children and 71 were adults. This tragedy caused the American Congress to approve the Food, Drug, and Cosmetic Act in 1938, under which pharmaceutical product manufacturers were directed to show scientific evidences of the safety of the drugs before marketing. ${ }^{4}$ The thalidomide disaster is a milestone in the origin and further development of pharmacovigilance. Thalidomide was introduced in 1957 and was widely prescribed as a treatment for morning sickness, but there were reports of a congenital abnormality in fetus called as phocomelia. Thus, the words thalidomide and birth defects became permanently linked as a result of consumption of thalidomide as a sedative in pregnancy. In 1962, after multiple reports of phocomelia, it was discontinued. ${ }^{5}$ Thus, in 1962, 
the Kefauver Harris amendment was approved, which required scientific evidences of efficacy and safety of drugs before marketing in humans. ${ }^{6}$ Due to pooling of existing data on adverse drug reactions (ADRs), the WHO started a program for International Drug Monitoring in 1968. Initially, a pilot project was launched in 10 countries, which was established with national reporting systems for ADRs. As this network has expanded significantly, more countries worldwide have established national pharmacovigilance centers for the monitoring of ADRs. Currently, 134 countries are participating in the pharmacovigilance program, ${ }^{2}$ which is centrally coordinated by the WHO with its collaborating center in Uppsala, Sweden. The collaborating center maintains the global ADR database in software called as Vigibase. At present, the database contains more than four million ADR reports. ${ }^{7}$ The European Medicines Agency (EMA) was founded in 1995, and it is a decentralized body of the European Union (EU). Its main responsibility is protection and promotion of public and animal health through the evaluation and supervision of medicines for human and veterinary use. The EMA can be considered the hub of a European medicines network, comprising over 40 national competent authorities, the European Commission, the European Parliament, and a number of other decentralized EU agencies. ${ }^{8}$ The agency works closely with its European partners to build the best possible regulatory system for medicines for Europe and to protect the health of its citizens. Flow Chart 1 explains the flow of ADRs at regional, national, and international level.

\section{History of Pharmacovigilance in India}

The origin of pharmacovigilance in India goes back to 1986, when a formal ADR monitoring system consisting of 12 regional centers, each covering a population of 50 million, was proposed. ${ }^{10}$ However, nothing much happened until a decade later when in 1998, India joined the WHO ADR monitoring program based in Uppsala,

Flow Chart 1: Data at regional, national, and international levels ${ }^{9}$

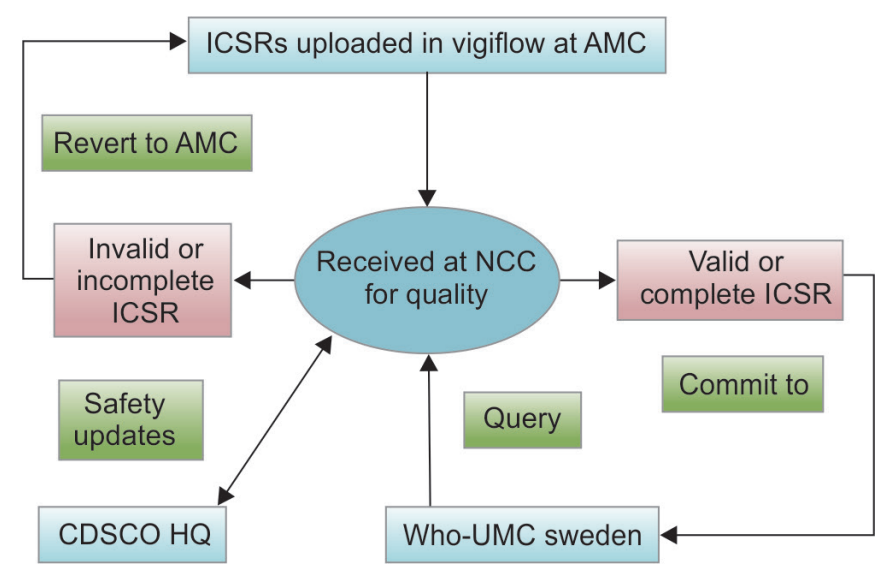

Sweden. This attempt was unsuccessful and hence, from January 1, 2005, the WHO-sponsored and World Bank-funded National Pharmacovigilance Programme of India (PvPI) was made operational. ${ }^{11}$ The National Pharmacovigilance Program established in January 2005 was monitored by the National Pharmacovigilance Advisory Committee based in the Central Drugs Standard Control Organization (CDSCO), New Delhi. Two zonal centers - the South-West zonal center (located in the Department of Clinical Pharmacology, Seth GS Medical College and KEM Hospital, Mumbai) and the North-East zonal center (located in the Department of Pharmacology, All India Institute of Medical Sciences, New Delhi) - were to collate information from all over the country and send it to the Committee as well as to the Uppsala monitoring center in Sweden. Three regional centers would report to the Mumbai center and two to the New Delhi one. Each regional center in turn would have several peripheral centers reporting to it. At present, there are 26 peripheral centers. The program has three broad objectives: The short-term objective is to foster a reporting culture, the intermediate objective is to involve a large number of HCPs in the system in information dissemination, and the long-term objective is for the program to be a benchmark for global drug monitoring. The concept of pharmacovigilance is not new to India, as the pharmacovigilance program has been operational since 1998, when India decided to join the Uppsala center for adverse event monitoring. The CDSCO, Directorate General of Health Services, under the aegis of the Ministry of Health and Family Welfare, Government of India, in collaboration with Indian Pharmacopoeia Commission, Ghaziabad, which is a National Coordinating Centre (NCC), has initiated a nation-wide pharmacovigilance program for protecting the health of the patients by monitoring ADRs and hence assuring the drug safety.

\section{Adverse Drug Reaction Monitoring Centers under PvPI}

Adverse drug reaction monitoring centers (AMCs) under PvPI ${ }^{11,12}$ play a vital role in the collection and follow-up of ADR reports from the patients. They are set up across India to collect the adverse event information from patients. These AMCs are the Medical Council of India (MCI)-approved medical colleges and hospitals, medical/central/autonomous institutes, public health programs, or corporate hospitals. They are responsible for collecting the adverse event information from the patients, performing follow-up with them to check the completeness of the ADR reports as per Standard Operating Procedures, entering information in the prescribed software (Vigiflow), and sending them 
Flow Chart 2: Guidance document for spontaneous ADR reporting, version: $1.0^{13}$ Governance structure

National pharmacovigilance programme of India-head auarters

Central drugs standards control organisation ministry of health and family welfare, government of India

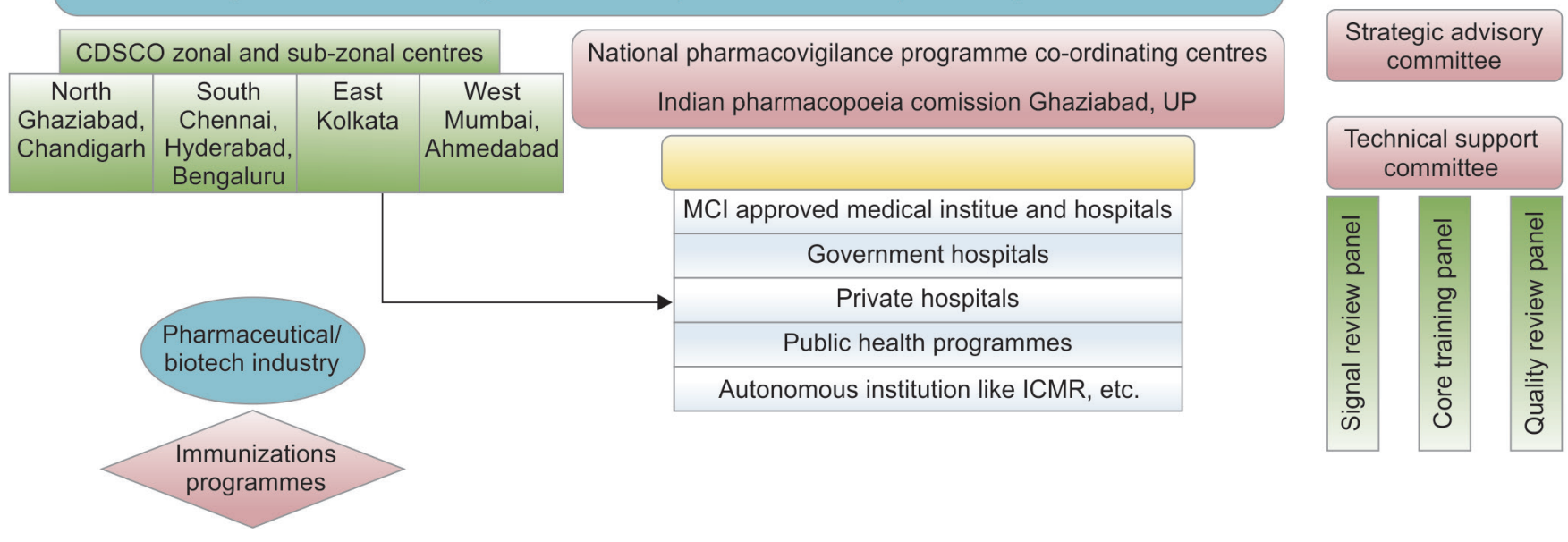

to NCC via the same software. Some AMCs are also responsible for providing training and technical support at the regional level. The PvPI started with the enrolment of $>22$ AMCs across the country in 2010, which has increased to 90 by the end of 2012, 60 of which are phase I AMCs and 30 are phase II AMCs. All the 90 AMCs are categorized into four zones, i.e., North, South, East, and West, as per zonal offices of CDSCO in India and are functioning under the NCC. There are more than 2,000 pharmacy colleges, 90 Institute of PharmD, more than 200 dental institutes, and more than 320 nursing institutes all over India. All PharmD, pharmacy practice, dental, and paramedical colleges are associated with patient care by providing safe and effective medication. For robust pharmacovigilance, these colleges will be included as AMCs under this program in the years to come. There are more than 360 MCI-approved medical colleges in India, of which 194 colleges are private. All MCI-approved colleges and Pharmacy Council of India-approved pharmacy colleges having pharmacy practice and PharmD will be included in PvPI through proper channel. All MCIapproved medical colleges and hospitals in the program covering north, south, east, and west of India will be enrolled, and ultimately, all government and corporate hospitals will be enrolled in the program covering entire India (Flow Chart 2).

\section{Aims of Pharmacovigilance Program}

It is due to pharmacovigilance program ${ }^{14,15}$ in India that the regulatory agencies, media, and consumers have become more aware about the benefits and risks associated with the use of medicines. The various aims of PvPI are:
- To monitor ADRs in the Indian population

- To create awareness among HCPs about the importance of ADR reporting in India

- To generate evidence-based data/recommendations on the safe use of drugs

- To support the CDSCO in formulating safety-related regulatory decisions of medicines

- To monitor benefit-risk profile of drugs and communicate information to all key stakeholders

- To create a national center of excellence at par with global drug safety monitoring standards

- To identify and analyze new signal from the reported cases

- To communicate the safety information on use of drugs to various stakeholders to minimize the risk

- To collaborate with other national centers for the exchange of information on adverse drug reports

- To promote rational use of medicine.

\section{WHY WE NEED PHARMACOVIGILANCE/ ADR MONITORING?}

- Drug trials in animals and humans (phase I-III) do not provide detailed information on adverse reactions to drugs faced by practitioners. The information on drug therapy related adverse effects such as rare/ serious ADRs/drug interactions/chronic toxicity and use in special populations (e.g., pregnant women, geriatrics, and pediatrics) are not available from the drug information literature, such as package inserts, drug manuals, phase III clinical trials, etc. Thus, pharmacovigilance helps in evaluating effectiveness, tolerability, and safety of drugs while prescribing treatment to patients. This helps to identify and control 
severe adverse reactions seen with individual drugs and hence promotes a comprehensive assessment of the benefit/risk profile of drugs as they are utilized by the patients.

- Globalization under the World Trade Organization has changed the world and also has a strong impact on the pharmaceutical sector. It is bringing different challenges related to drug safety. For example, prescriptions as well as nonprescription drugs are becoming increasingly available to the general public in all countries through Internet. Monitoring the safety and quality of drugs is a challenge. Thus, there is a need for a better and more efficient level of international pharmacovigilance.

- While major advancements of pharmacovigilance have taken place in the Western world, not much has been achieved in India. There is an immense need to understand the importance of pharmacovigilance and how it impacts patient safety and treatment.

- The adverse case reports on clioquinol-induced subacute myelo-optico neuropathy ${ }^{16}$ and phenylpropanolamineinduced intraventricular hemorrhage $\mathrm{e}^{17}$ in patients have laid down the importance of ADR reporting to PvPI as in such cases, the Indian regulatory agencies cannot count on the experience of other markets to assess benefit-risk balance of a drug.

- India is becoming a hub for clinical research activities due to its large population, high enrolment rate, and low cost. The lag period from drug discovery to marketing in India like in the United States, Europe, Japan, and other countries has decreased considerably the information on ADRs/long-term safety data. This is clear by the fact that all the high-profile drugs that have been recently withdrawn in other countries, such as nimesulide, flupentixol-melitracen combination, metamizole, phenylpropanolamine, and phenolphthalein, are still available in the Indian market. ${ }^{18}$

\section{PHARMACOVIGILANCE AND DRUG SAFETY MONITORING}

Pharmacovigilance plays an important role in management and ensuring safety of treatment in patients. The various ways that help in this regard are as follows:

- Postmarketing drug safety monitoring: This includes detection of drug interactions, measuring the environmental burden of medicines used in large populations, assessing the contribution of "inactive" ingredients to the safety profile, systems for comparing safety profiles of similar medicines, surveillance of the adverse effects on human health of drug residues in animals, e.g., antibiotics, and hormones. The Council for International Organizations of Medical Sciences report on benefit-risk assessment of medicines after marketing has contributed to a more systematic approach to determining the merit of available medicines. ${ }^{19}$

- Pharmacovigilance in national drug policy: The provision of good quality, safe, and effective medicines and their appropriate use is the responsibility of national governments. ${ }^{20}$ Multidisciplinary collaboration is of great importance; in particular, links need to be forged between various departments of the Ministry of Health and also with other stakeholders, such as the pharmaceutical industry, universities, nongovernmental organizations (NGOs), and those professional associations having responsibility for education on rational use of medicines and pharmacotherapy monitoring. Six key elements of pharmacovigilance in national drug policy are as follows:

1. Establishment of national pharmacovigilance systems for the reporting of adverse events, including national and, if appropriate, regional pharmacovigilance centers.

2. Development of legislation/regulation for medicine monitoring.

3. National policy development (to include costing, budgeting, and financing).

4. Continuing education of health care providers on safe and effective pharmacotherapy.

5. Provision of up-to-date information on adverse reactions to professionals and consumers.

6. Monitoring the impact of pharmacovigilance through process indicators and outcome.

- Pharmacovigilance in disease control public health programs: The monitoring of medicine safety in countries where there is no regulatory or safety monitoring system in place, or in remote areas with little or no health care surveillance or infrastructure, has been identified as a matter for concern. The problems are especially apparent in situations that involve the use of medicines in specific communities, e.g., for the treatment of tropical diseases, such as malaria, leishmaniasis, and schistosomiasis and for the treatment of human immunodeficiency virus/acquired immune deficiency syndrome and tuberculosis. ${ }^{21}$ The WHO recommends that pharmacovigilance should be a priority for every country with public health disease control programs. ${ }^{22}$

- Drug utilization studies (DUSs): Drug utilization patterns are a major determinant in drug safety. For instance, the use of injectable medicines is more common in developing countries. ${ }^{23}$ Direct advertising to the consumer of prescription medicines has become commonplace in many countries. With this information, patients feel more able to make their 
Pharmacovigilance in India and its Impact in Patient Management

own therapeutic decisions, without assistance from the doctor or pharmacist. The result has been increasing self-medication, licit and illicit sale of medicines over the Internet, and overprescribing by doctors on patients' demand. This has had considerable effect on increased prescribing of drugs. ${ }^{24}$ Such public health programs, however, need not focus only on patients but could be used for the benefit of the general public as well. Such awareness building and educational initiatives should also include children and elderly populations and could be greatly facilitated through partnerships with the media, educational institutions, and governmental and NGOs. The success of WHO International Drug Monitoring Programs is entirely dependent on the contributions of national pharmacovigilance centers. ${ }^{25}$ Thus, pharmacovigilance has its importance in DUS by bridging more closely with other areas, such as public health, rational use of drugs, evidence-based drug use, pharmacoeconomics, ecopharmacovigilance, and pharmacogenetics. ${ }^{26}$

\section{IMPACT OF PHARMACOVIGILANCE IN PATIENT TREATMENT}

Knowledge of pharmacovigilance has improved the knowledge of the treating physician about various drug-related events. The various benefits are as follows.

\section{Impact on Chronic Kidney Disease/ End-Stage Renal Disease Treatment}

Patients with chronic kidney disease (CKD) and end-stage renal disease have significant challenges and complex therapeutic regimens. The presence of multiple comorbidities, such as cardiovascular disease, hypertension, and diabetes, requires the use of a variety of pharmaceutical interventions in addition to those needed to manage renal insufficiency. ${ }^{27}$ Adding to this complex situation is the impact of chronic renal replacement therapy, which has its own set of adverse effects, but where drug effects may play either a causative role or may interact with an evolving complication. The impact of a drug safety issue in a patient with end-stage renal failure may operate through different mechanisms and could include:

- Direct patient harm from the clinical sequelae of the adverse event. $^{28}$

- An interaction with the dialysis therapy itself (e.g., the interaction of angiotensin-converting enzyme inhibitors with specific polyacrylonitrile hemodialysis membranes, causing an acute hypersensitivity reaction). ${ }^{29}$

- The risk of intravenous immunoglobulin in inducing renal failure as was evident from case series studies. ${ }^{30}$
Since information related to the use of drugs in the CKD/dialysis population is at best limited, it is important that nephrologists and other health care workers managing patients with end-stage renal failure should understand the concept and implementation of pharmacovigilance. This will contribute to enhanced patient safety for this high-risk population and mirror the drive by nephrology organizations to develop patient safety indicators to improve CKD-specific treatment. ${ }^{31}$

\section{Impact on Other Clinical Situations}

- Withdrawal of a specific lot of the peritoneal dialysis (PD) solution, Nutrineal ${ }^{\mathrm{TM}}$ (Baxter Healthcare Corporation, Deerfield, IL, USA), which occurred in Europe in October 2010.32 Baxter began receiving a number of reports of aseptic peritonitis associated with one specific lot of Nutrineal. While the reporters informed Baxter of the peritonitis, many gave extremely limited details, providing no information on laboratory investigations, minimal information on whether the patient improved upon discontinuation of the Nutrineal, not providing information on other PD solutions that may have played a role in the adverse event, and not confirming the specific lot of Nutrineal in use at the time of the events. The lack of such details made it extremely challenging to analyze this signal; however, as further details were collected during follow-up calls to HCPs, Baxter was able to identify the lot association and take necessary action to withdraw this lot from the market.

- Icodextrin and device interaction: Extraneal ${ }^{\mathrm{TM}}$ (icodextrin) (Baxter Healthcare Corporation) is a PD solution containing the colloid osmotic agent icodextrin, a starch-derived water-soluble glucose polymer. While Extraneal was closely monitored and assessed during clinical trials, an unanticipated, rare adverse event did not emerge until Extraneal was used by a larger population. Icodextrin, the osmotic agent in Extraneal, is metabolized into oligosaccharides including maltose and other higher molecular weight molecules. Certain glucometers are considered "nonspecific" and measure not only glucose but also metabolites, such as maltose. The presence of maltose can lead to falsely elevated glucose readings, ${ }^{33,34}$ which could in turn lead to the administration of more insulin than needed in patients using these glucometers. Administration of more insulin than needed can cause hypoglycemia, which may lead to loss of consciousness, coma, neurologic damage, and death. Additionally, falsely elevated blood glucose measurements due to maltose interference may mask true hypoglycemia, which left untreated can result in similar consequences. Falsely elevated glucose levels may be measured up to 2 weeks 
following cessation of icodextrin therapy. This particular issue did not occur in the Extraneal clinical trials, but was identified as Baxter began receiving cases of falsely elevated glucose readings after product launch. This life-threatening issue is best exemplified by a published case report of a 59-year-old patient on Extraneal who was admitted for an elective procedure. ${ }^{35}$ During the preoperative period, she communicated to the HCPs that, due to her Extraneal use, she required the use of a specific glucometer. Unfortunately, when the patient was transferred postoperatively to the intensive care unit (ICU), this message was not transferred with her. The readings on the nonspecific glucose handheld monitors in the ICU provided an overestimation of the glucose level, leading to the administration of too much insulin. The patient developed hypoglycemic encephalopathy and eventually died at an extended care nursing facility.

- Quinolones and tendon rupture: The use of quinolone antibiotics has been associated with the development of tendon rupture in animal studies. This risk was identified largely based on postmarketing rather than clinical trial data and illustrates an additional important point. Many clinicians may not consider reporting a tendon rupture to the manufacturer of an antibiotic, believing that it is "biologically not possible," yet this adverse event was first reported in medical journals as case reports seen in the postmarketing setting. This adverse event has led to boxed warnings in all quinolone labels. This is of particular relevance in dialysis patients since quinolone use is not uncommon in this population. $^{36}$

- Drug-induced hepatic failure: It is a frequent cause of withdrawals of drugs from the market. Troglitazone used in diabetes is an example. It was withdrawn following cases of hepatic toxicity found in postmarketing surveillance. Hepatic reactions are rare, and therefore difficult to detect prior to marketing of a drug. A trial involving 30,000 patients would be required to detect with reasonable certainty a reaction occurring in one patient in $10,000 .{ }^{37}$ As a result, postmarketing surveillance for hepatic reactions to new drugs is crucial. Drug-induced liver disease is a serious reaction and should be reported to the pharmacovigilance center immediately. This applies also to new drugs with known history of hepatotoxicity. ${ }^{38}$

\section{CONCLUSION}

Thus, it can be concluded that pharmacovigilance is an important tool in ensuring patient safety as by reporting the ADRs, the patient morbidity and mortality can be reduced. This also enhances the knowledge of prescribers about drug-related events, and thus appropriate modification in the treatment can be done to benefit the patients.

\section{REFERENCES}

1. World Health Organization. The importance of pharmacovigilance - safety monitoring of medicinal products [Internet]. Geneva: World Health Organization; 2002 [cited 2016 Sep 21]. Available from: http://apps.who.int/medicinedocs/pdf/ s4893e/s4893e.pdf.

2. Pharmacovigilance [Internet]. World Health Organization. [cited 2016 Sep 21]. Available from: http:/ /www.who.int/medicines/ areas/quality_safety/safety_efficacy/pharmvigi/en/.

3. US Food and Drug Administration. History [Internet]. Silver Spring: US Food and Drug Administration; 2013 [cited 2016 Sep 21]. Available from: http://www.fda.gov/AboutFDA/ WhatWeDo/History/default.htm.

4. Elixir sulfanilamide [Internet]. Wikipedia, The Free Encyclopedia; 2012 Jun, at 15:27 UTC [cited 2016 Sep 21]. Available from: http://en.wikipedia.org/wiki/Elixir_sulfanilamide; http:/ / www.ivtnetwork.com/sites/default/files/IVTGXPxxxx_CoverStory-2\%20pr1.pdf.

5. Ridings JE. The thalidomide disaster, lessons from the past. Methods Mol Biol 2013;947:575-586.

6. Promoting safe and effective drugs for 100 years [Internet]. U.S. Food and Drug Administration. [cited 2016 Sep 21]. Available from: http://www.fda.gov/AboutFDA/What WeDo/History/CentennialofFDA/CentennialEditionof FDAConsumer/ucm093787.htm.

7. Kumar A. Past, present and future of pharmacovigilance in India. Syst Rev Pharm 2011 Jan;2(1):55-58.

8. Pharmacovigilance: regulatory and procedural guidance [Internet]. European Medicines Agency. [cited 2016 Sep 21]. Available at: http:/ / www.ema.europa.eu/ema/index.jsp?curl=pages / regulation/document_listing/document_listing_000199.jsp.

9. Pharmacovigilance programme of India: guidance document for spontaneous adverse drug reaction reporting. Version 1.0 Published by Indian Pharmacopoeia Commission. National Coordination Centre - Pharmacovigilance Programme of India, Ministry of Health \& Family Welfare, Government of India. Printed by Nutech Photolithographers, B-240, Okhla Industrial Area, Phase-I, New Delhi.

10. Kulkarni RD. Reporting systems for rare side effects of nonnarcotic analgesics in India. Problems and opportunities. Med Toxicol 1986;1(1 Suppl 1):110-113.

11. Protocol for National Pharmacovigilance Programme [Internet]. CDSCO, Ministry of Health and Family Welfare, Government of India; 2004 Nov [cited 2015 May 25]. Available from: http:/ / www.cdsco.nic.in/html/Pharmacovigilance $\% 20$ Protocol\%20.pdf.

12. Kshirsagar NA, Karande SC, Potkar CN. Adverse drug reaction monitoring in India. J Assoc Physicians India 1993 Jun;41(6):374-376.

13. Suke SG, Kosta P, Negi H. Role of pharmacovigilance in India: an overview. Online J Public Health Inform 2015 Jul;7(2):e223.

14. Bavdekar SB, Karande S. National pharmacovigilance program. Indian Pediatr 2006 Jan;43(1):27-32.

15. CIOMS. Benefit-risk balance for marketed drugs: evaluating safety signals - report of CIOMS working group IV. Geneva: CIOMS; 1998 [cited 2016 Sep 21]. Available from: http:/ / www.cioms.ch/publications/g4-benefit-risk.pdf. 
16. Wadia NH. Clioquinol-subacutemyelo-opticoneuropathy (SMON) in Indians. Some observations on SMON from Bombay. J Neurol Neurosurg Psychiatry 1977;40(3):268-275.

17. Prasad A, Bhoi KK, Bala K, Anand KS, Pal HK. Phenylpropanolamine-induced intraventricular hemorrhage. Neurol India 2003 Mar;51(1):117-118.

18. List of drugs prohibited for manufacture and sale through gazette notifications under section 26a of drugs and cosmetics act 1940 by the ministry of health and family welfare. [cited 2016 Sep 21]. Available from: http:/ /www.cdsco.nic.in/writereaddata/ drugs \%20banned\%20in\%20the\%20country2.pdf.m.

19. The safety of medicines in public health programmes: pharmacovigilance an essential tool [Internet]. WHO Library Cataloguing-in-Publication Data 2006. [cited 2016 Sep 21]. Available from: http://www.who.int/medicines/areas/ quality_safety/safety_efficacy/Pharmacovigilance_B.pdf.

20. Pharmacovigilance: ensuring the safe use of medicines - WHO policy perspectives on medicines, No. 009 [Internet]; 2004 Oct [cited 2016 Sep 21];6. Available from: http:/ /apps.who.int/ medicinedocs/en/d/Js6164e/3.1.html.

21. Kane A, Lloyd J, Zaffran M, Simonsen L, Kane M. Transmission of hepatitis $B$, hepatitis $C$ and human immunodeficiency viruses through unsafe injections in the developing world: model-based regional estimates. Bull World Health Organ 1999;77(10):801-807.

22. Looking at the pharmacovigilance: ensuring the safe use of medicines - WHO policy perspectives on medicines. Geneva: World Health Organization; 2004 [cited 2016 Sep 21]. Available from: http://www.whqlibdoc.who.int/hq/2004/ WHO_EDM_2004.8.pdf.

23. Bapna JS, Tripathi CD, Tekur U. Drug utilisation patterns in the Third World. Pharmacoeconomics 1996 Apr;9(4): 286-294.

24. de Vries CS, Duggan CA, Tromp TF, de Jong-van den Berg LT. Changing prescribing in the light of tolerability concerns: how is this best achieved? Drug Saf 1999 Sep;21(3):153-160.

25. WHO Expert Committee. The selection of essential drugs. Technical report series 615. Geneva: World Health Organization; 1977.

26. Shalini S, Ravichandran V, Mohanty BK, Dhanaraj SK, Saraswathi R. Drug utilization studies - an overview. Int J Pharm Sci Nanotechnol 2010 Apr;3(1):803-810.

27. McCann L, Hoefs M. Multidisciplinary team care for CKDMBD. Achieving KDIGO guideline recommendations in the bundling era. Nephrol News Issues 2014 Apr;28(4):24-26.
28. García Doladé N, Cereza García G, Madurga Sanz M, Montero Corominas D. [Risk of hypercalcemia and hipervitaminosis D induced by calcifediol. Review of cases reported to the Spanish Pharmacovigilance System]. Med Clin (Barc). 2013 Jul;141(2):88-89.

29. Verresen L, Waer M, Vanrenterghem Y, Michielsen P. Angiotensin-converting-enzyme inhibitors and anaphylactoid reactions to high-flux membrane dialysis. Lancet 1990 Dec;336(8727):1360-1362.

30. Moulis G, Sailler L, Sommet A, Lapeyre-Mestre M, Montastruc JL. French Association of Regional Pharmacovigilance Centers. Exposure to inhibitors of the renin-angiotensin system is a major independent risk factor for acute renal failure induced by sucrose-containing intravenous immunoglobulins: a case-control study. Pharmacoepidemiol Drug Saf 2012 Mar;21(3):314-319.

31. Fink JC, Joy MS, St Peter WL, Wahba IM. ASN Chronic Kidney Disease Advisory Group. Finding a common language for patient safety in CKD. Clin J Am Soc Nephrol 2012 Apr;7(4):689-695.

32. News and press release archive. European Medicines Agency recommends action plan to deal with possible presence of endotoxins in Baxter peritoneal dialysis solutions [Internet]. [cited 2016 Sep]. Available from: http://www.ema.europa.eu/ema/ index.jsp?curl=pages/news_and_events/news/2010/12/ news_detail_001170.jsp\&mid=WC0b01ac058004d5c1.

33. GlucoseSafety.com. Extraneal company core data sheet. Deerfield (IL): Baxter Healthcare Corporation; 2007 [cited 2016 Sep 21]. Available from: http:/ / www.glucosesafety.com/us/pdf/ extraneal_pi.pdf.

34. Jacob D, Marrón B, Ehrlich J, Rutherford PA. Pharmacovigilance as a tool for safety and monitoring: a review of general issues and the specific challenges with end-stage renal failure patients. Drug Healthc Patient Saf 2013 Apr;5:105-112.

35. Kroll HR, Maher TR. Significant hypoglycemia secondary to icodextrin peritoneal dialysate in a diabetic patient. Anesth Analg 2007 Jun;104(6):14731474.

36. Basic-Jukic N, Juric I, Racki S, Kes P. Spontaneous tendon ruptures in patients with end-stage renal disease. Kidney Blood Press Res 2009;32(1):32-36.

37. Ferner RE. Newly licensed drugs. BMJ 1996 Nov;313(7066): 1157-1158.

38. Sgro C, Clinard F, Ouazir K, Chanay H, Allard C, Guilleminet C, Lenoir C, Lemoine A, Hillon P. Incidence of drug-induced hepatic injuries: a French population-based study. Hepatology 2002 Aug;36(2):451-455. 